\title{
Power Conversion System Operation Algorithm for Efficient Energy Management of Microgrids
}

\author{
Kwang-Su Na ${ }^{1}$, Jeong Lee ${ }^{1}$, Jun-Mo Kim ${ }^{2}{ }^{\mathbb{D}}$, Yoon-Seong Lee ${ }^{1}$, Junsin $\mathrm{Yi}^{1}{ }^{1}$ and Chung-Yuen Won ${ }^{1, *}$ \\ 1 Department of Electrical and Computer Engineering, Sungkyunkwan University, Suwon 16419, Korea; \\ neolife7@skku.edu (K.-S.N.); leejeong1@skku.edu (J.L.); ysle2@skku.edu (Y.-S.L.); junsin@skku.edu (J.Y.) \\ 2 Interdisciplinary Program in Photovoltaic System Engineering, Sungkyunkwan University, \\ Suwon 16419, Korea; ksho4807@skku.edu \\ * Correspondence: woncy@skku.edu; Tel.: +82-031-290-7164
}

check for updates

Citation: Na, K.-S.; Lee, J.; Kim, J.-M.; Lee, Y.-S.; Yi, J.; Won, C.-Y. Power Conversion System Operation Algorithm for Efficient Energy Management of Microgrids. Electronics 2021, 10, 2791. https:// doi.org/10.3390/electronics10222791

Academic Editor: Ali Mehrizi-Sani

Received: 26 October 2021

Accepted: 12 November 2021

Published: 14 November 2021

Publisher's Note: MDPI stays neutral with regard to jurisdictional claims in published maps and institutional affiliations.

Copyright: (C) 2021 by the authors. Licensee MDPI, Basel, Switzerland. This article is an open access article distributed under the terms and conditions of the Creative Commons Attribution (CC BY) license (https:// creativecommons.org/licenses/by/ $4.0 /)$.

\begin{abstract}
This paper investigates the operation of each power conversion system (PCS) for efficient energy management systems (EMSs) of microgrids (MGs). When MGs are linked to renewable energy sources (RESs), the reduction in power conversion efficiency can be minimized. Furthermore, energy storage systems (ESSs) are utilized to manage the surplus power of RESs. Thus, the present work presents a method to minimize the use of the existing power grid and increase the utilization rate of energy generated through RESs. To minimize the use of the existing power grid, a PCS operation method for photovoltaics (PV) and ESS used in MGs is proposed. PV, when it is directly connected as an intermittent energy source, induces voltage fluctuations in the distribution network. Thus, to overcome this shortcoming, this paper utilizes a system that connects PV and a distributed energy storage system (DESS). A PV-DESS integrated module is designed and controlled for tracking constant power. In addition, the DESS serves to compensate for the insufficient power generation of PV. The main energy storage systems (MESSs) used in MGs affect all aspects of the power management in the system. Because MGs perform their operations based on the capacity of the MESS, a PCS designed with a large capacity is utilized to stably operate the system. Because the MESS performs energy management through operations under various load conditions, it must have constant efficiency under all load conditions. Therefore, this paper proposes a PCS operation algorithm with constant efficiency for the MESS. Utilizing the operation algorithm of each PCS, this paper describes the efficient energy management of the MG and further proposes an algorithm for operating the existing power grid at the minimum level.
\end{abstract}

Keywords: microgrid (MG); energy management system (EMS); power conversion system (PCS); PV-DESS integrated module; main energy storage system (MESS)

\section{Introduction}

The system configuration of a microgrid (MG) can be categorized into three types: AC MGs, DC MGs, and AC/DC hybrid MGs [1]. Recently, the proportion of renewable energy sources (RESs) in existing power systems has been gradually increasing. Among them, the proportions of photovoltaics (PV) and wind turbines (WTs) are the greatest [2]. In the early stage of MG development, many studies were conducted, mainly on the AC MG [3-5]. However, due to the recent increase in load and intermittent energy sources, such as PV and WTs, batteries are concurrently used [6,7]. Thus, by reducing the steps of power conversion, a system configuration with DC MG has many advantages in terms of energy efficiency. Power conversion losses occur in the range of $5-15 \%$ of the total power generation, depending on the number of power conversion steps [8]. Accordingly, systems are being upgraded to DC MGs and AC/DC hybrid MGs to reduce the power conversion loss.

Reference [9] proposed power control based on the battery state of charge (SoC) of the energy management system (ESS) to maintain the stability of the DC MG. In the SoC-based 
MG operation, the converters of the RESs perform operations according to the battery's state. This is disadvantageous, in that it is difficult to maximize the utilization rate of the RESs. Reference [10] proposed predictive control for secondary and tertiary control for the efficient energy management of an MG. It is highly useful to learn the change in power generation through time from the system. However, power grid operation is complex and variable due to increasing loads [11]. A paper was also presented to increase the utilization rate of RESs in MGs [12]. Through the generation of such RESs, energy is stored and power is supplied to the load and users, which is advantageous in that the system does not utilize the conventional power grid and that the amount of use of RESs can be maximized. However, the system is unstable, because the battery is charged through the power generation of the RESs, and the power is supplied to the load using the charged ESS. Thus, to stably operate the system, the battery is charged in the DC MC by using a voltage source converter (VSC) [13]. In addition, surplus power can be sold or used for the AC load by using a voltage source inverter (VSI) [14]. Due to its linkage with several RESs, an MG requires efficient energy management. This paper proposes an EMS for reducing the operating cost of MGs by increasing the utilization rate of RESs and minimizing the use of the conventional power grid through the MG EMS.

ESS is used for the energy management of MGs. The battery, which accounts for most of the cost [15] in the ESS, requires stability. Furthermore, the ESS is utilized for power management through the power generation of several RESs of an MG [16]. Reference [17] constructed a household ESS using Li-ion batteries, and there are studies on the MG using Li-ion batteries [18], the characterization of Li-ion batteries [19,20], and thermal runaway of batteries [21]. Because the isolated MG should be able to supply power to the load using the ESS alone, it is related to the load carrying capacity of the MG [16,22]. Typically, the ESS of an MG is designed to have a significantly larger capacity compared to the PCS of other RESs [23,24]. The EMS of an MG is operated based on the battery SoC [9]. In addition, the power generation through each RES and the power supplied to the load are measured for the EMS. This amount of power is used to calculate the charge/discharge power of the ESS. However, the aforementioned capacity difference in the PCS results in the significantly long operation of the ESS under light load conditions. A typical power conversion device has low efficiency under light load conditions. Thus, when the power generated from the RES is stored in batteries, significant losses occur. Because these losses are detrimental to the MG's surplus power management, the MESS must maintain high efficiency under various load conditions. Given this, an algorithm with high efficiency under a light load for the MESS is proposed in this paper.

Among RESs, PV as an intermittent power source induces abnormal voltage and frequency variations in the conventional power grid [25]. In addition, there is a likelihood of surplus power, because power generation proceeds regardless of the load state of the system. For these reasons, previous studies have proposed systems linked with batteries [26,27]. Linkages with a supercapacitor [28] and hybrid systems $[29,30]$ have also been applied. A hybrid system has the advantage of maximizing battery life, while a high unit price is inevitable due to the PV, battery, and supercapacitor. Thus, to minimize the intermittent characteristics of the MG grid voltage, this paper configures a system by utilizing PV and DESS, as well as a two-stage system. DESS serves to compensate for the insufficient maximum power generation of $\mathrm{PV}$, and this paper proposes a constant power tracking algorithm for PV-DESS.

This paper describes the efficient energy management of an MG by using the highefficiency operation of all areas of the MESS, as well as the constant power tracking algorithm for the PV-DESS. Efficient energy management of MGs aims to increase the energy consumption of RESs and reduce the operating cost of MGs by minimizing the conventional power grid. 


\section{Proposed Operation Method of the Microgrid PCS}

This chapter describes the various PCSs constituting an MG. MGs are classified as grid-connected mode or islanded mode [31]. In the former, electricity can be purchased or sold by using the existing power grid. Thus, maximum profitability can be obtained in the operation of the MG. Because PV is an intermittent energy source, insufficient power generation can be overcome by linking PV to ESS, thereby enhancing MG system stability [32]. Figure 1 shows a block diagram of the MG proposed in this paper. VSC is utilized to maintain a stable MC system. VSC uses a two-level AD/DC converter and performs battery charging and power supply provision to the load. In addition, surplus power can be sold to the existing power grid. Thus, the operating cost of the MG should be minimized.
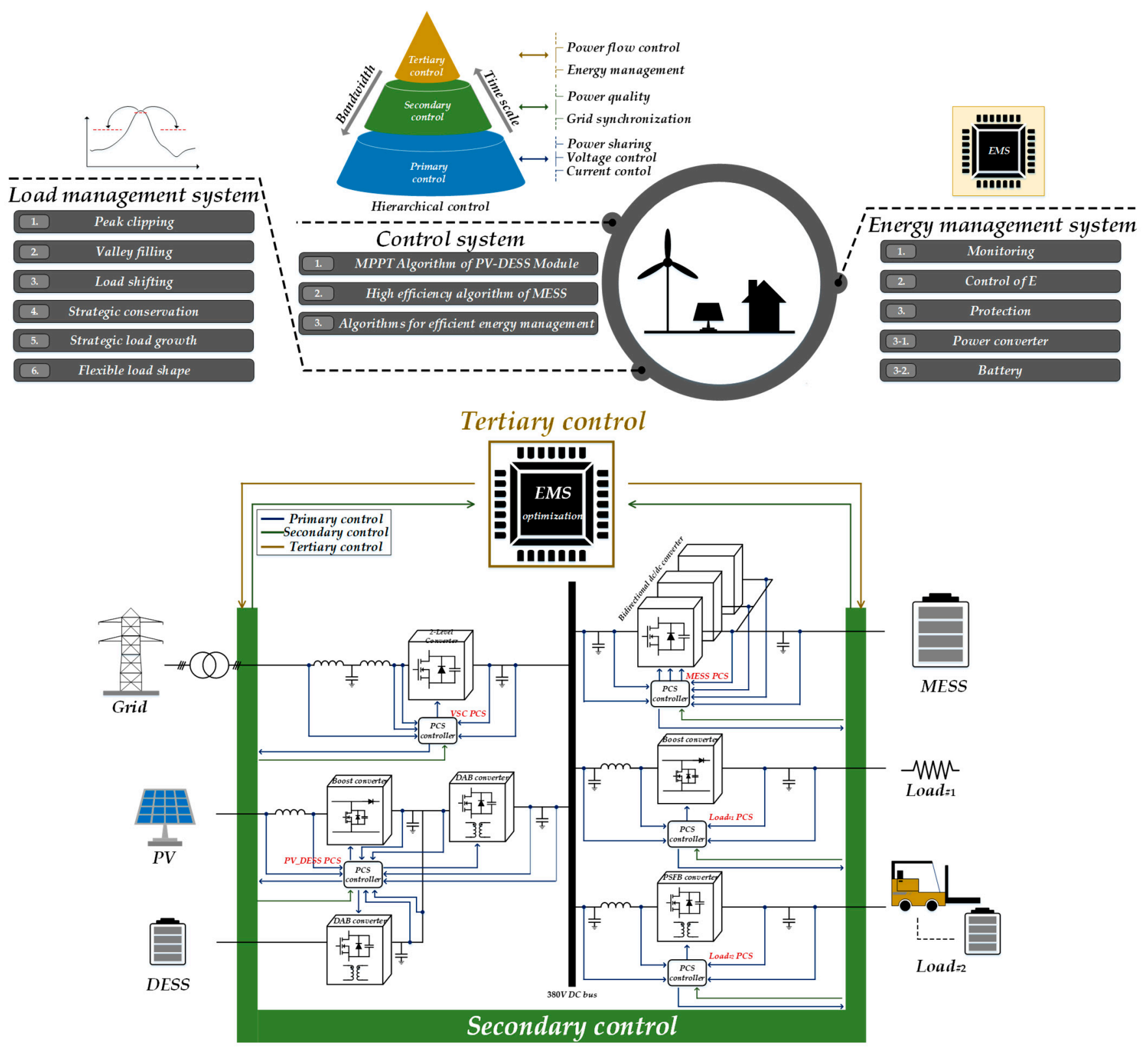

Figure 1. The proposed hierarchical control of MG.

The MESS uses a three-module PCS in a parallel structure. A buck-boost converter was used, and the number of modules changed depending on the amount of charge/discharge power of the MESS. Furthermore, to implement a high-efficiency PCS, a SiC MOSFET 
device was used. PV-DESS consists of two stages. PV uses a boost converter, and the DESS operates bidirectionally by utilizing a dual active bridge (DAB) converter. The DESS supports the maximum power generation at time period 13:00-15:00, which is the maximum power generation interval of PV. The charge/discharge cycle and $\mathrm{C}$ rate of the DESS can thus be minimized. For the load, a load supplying constant power and a charger load requiring high instantaneous power were used. A boost converter was used to supply constant power, and a phase shift full-bridge converter was utilized as a charger that requires high instantaneous power. Primary control was performed by the controller of each PCS, which is involved in voltage and current control. Thus, this is the lowest and fastest control level, and it typically operates with local measurements [33-35]. Secondary control is performed by supervising the tasks of the primary control, and the time scale is at the several-minute level [33-35]. Tertiary control is involved in the performance of the optimal energy management of an MG. Thus, it has the lowest level of control [33-35]. In addition, information from the sub-controllers and external data, such as power prices and the power consumption trends of the existing power grid, can be reflected for operation. The load management system handles the power consumption of the MG to reach predefined goals, such as the minimization of MG costs and the peak-to-average ratio. The consumers of MGs can directly change the power patterns used by the load through a load management system or financial incentives. The basic technology applied by the load management system operates based on clipping, filling, and modifying [36].

The $V_{\mathrm{dc}}$ bus, which is the distribution network voltage of the $\mathrm{MG}$, is $380 \mathrm{~V}$, and the hosting capacity $[33,34]$ is determined by the capacity of the MESS. The MG must stably supply the amount of power required by the load. PV, which is an intermittent energy source, is not able to stably supply the power to the load due to the difference in power generation, depending on many external environments. Thus, the load carrying capacity of the MG is related to the capacity of the MESS.

Among RESs, PV is a highly intermittent energy source and induces instability in frequency and voltage [35]. Thus, the battery is utilized to minimize the effects on the user and the power distribution network. This paper proposes a system that combines PV and a DESS to minimize these adverse effects. The PCS of a typical PV uses a onestage boost converter. This configuration has the advantage of high efficiency and low price for the system. In addition, PV controls the input power to target the maximum power generation, which simultaneously acts as a factor affecting the voltage of the power distribution network in the MG. Thus, in this study, we applied a two-stage system to minimize its effect on the distribution network and enable this system to control the voltage of the MG. Moreover, the DESS supplements the insufficient amount of electricity in the maximum power generation of PV. This is a method to extend the DESS replacement cycle due to a deteriorated battery by minimizing the charge/discharge cycle and $C$ rate of the DESS.

The MESS of an MG is a crucial factor in carrying capacity and energy management. The ratings of PCS used in most MGs are the same as those provided in previous studies [36,37]. The ESS to be installed has a relatively large capacity, whereas the PCSs of other renewable energy sources have a relatively small capacity. A typical power conversion device has low efficiency at light load, and high efficiency at heavy and rated loads [38,39]. Efficiency deviation is present as an error in predicting the battery state by measuring the RES power generation of the MG and the amount of power supplied to the load. This error increases the utilization rate of the existing power grid and the operating costs of the MG. Therefore, an MESS requires a PCS operation algorithm that maintains high efficiency across all load areas.

This chapter describes the control method and operation algorithm of each PCS.

\subsection{Constant Power Tracking Algorithm for the PV-DESS Integrated Module}

Because PV is a source of intermittent energy, its power generation fluctuates, resulting in surplus electricity depending on the load state. Therefore, extensive research has 
been conducted to manage the surplus electricity using batteries with PV. Reference [40] optimized the components of PV-ESS and the size of other design parameters. The authors discussed the effects of parameters such as the size of the battery bank and depth of discharge (DoD) on the battery life. Among batteries used in ESSs, lithium-ion batteries are widely used owing to their high power density [41,42]. Although the lithium-ion battery is capable of high C-rate discharge, it negatively affects the battery life [43]. The general type of integrated PV-DESS uses PV to store energy in batteries, which is consumed during the highest electric rate or peak load [44,45]. Therefore, it can maintain maximum power generation during peak load and the highest electric rate until the minimum SoC of the battery. However, the integrated PV-DESS module proposed in this study comprises two stages, with the aim to supply a constant level of output to the DC distribution network. Furthermore, the DESS supplements the insufficient power generation of PV. The DESS only supplies the electricity required to maintain PV power generation for an hour, thus minimizing the charge and discharge cycles of the battery.

Figure 2 shows the operation algorithm for the PV-DESS integrated module depending on the EMS of the MESS. The P\&O MPPT method, which is commonly used to perform MPPT control to maximize power generation, is used in the PV module. The P\&O MPPT method tracks the MPP by varying the input voltage reference by a certain amount in comparison to the output power.

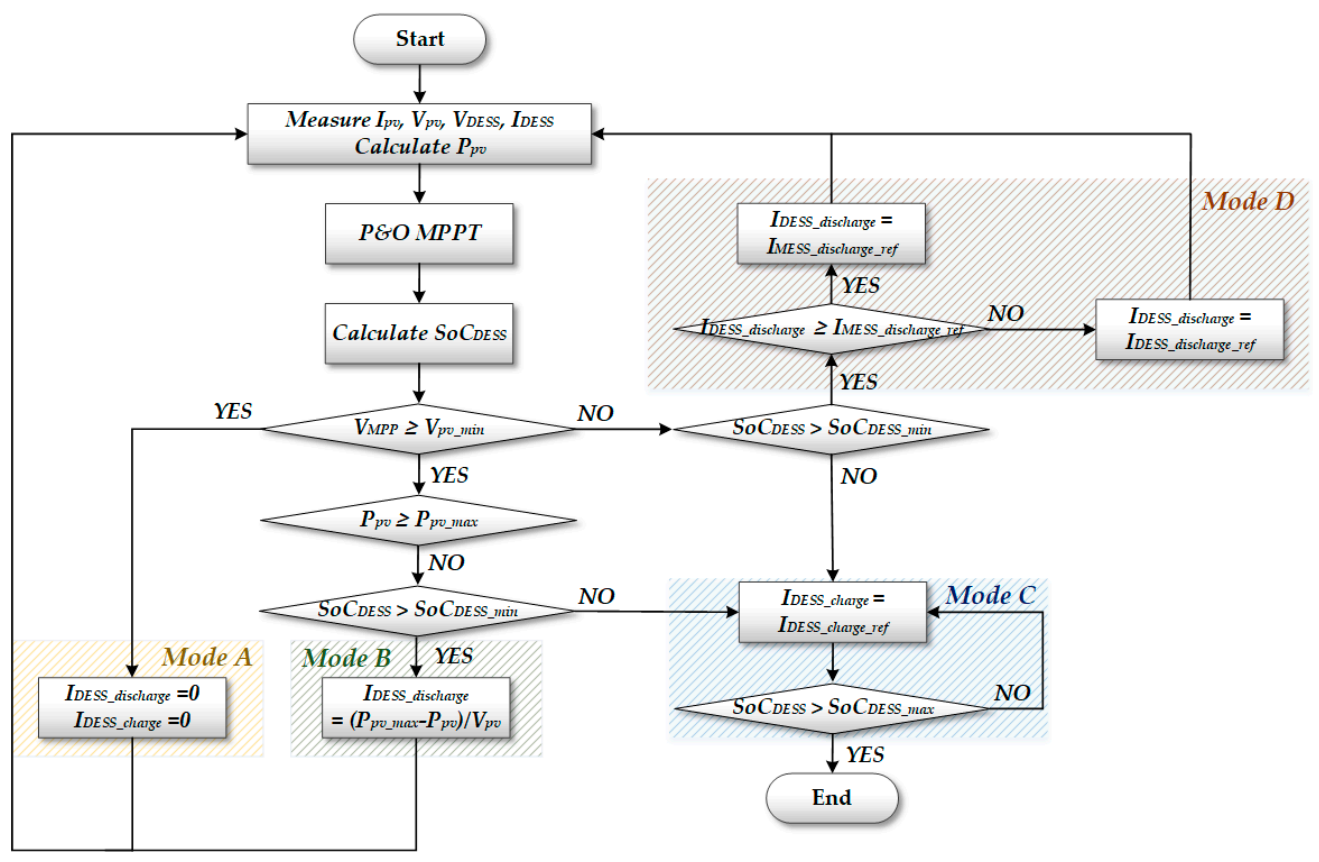

Figure 2. Operation algorithm of the PV-DESS integrated module.

$\mathrm{V}_{\mathrm{pv}}$ (the voltage of PV) and $\mathrm{I}_{\mathrm{pv}}$ (the current of PV) are monitored through sensors to control MPPT, and the $\mathrm{V}_{\text {DESS }}$ and $\mathrm{I}_{\text {DESS }}$ are sensed to determine the battery state of the DESS. Furthermore, after each mode operation, Ppv (the amount of electricity generated by PV) is estimated. The battery state of the DESS is determined by the SoC. SoC DESS represents the current battery state of the DESS, whereas SoC DESS_min $_{\text {and }}$ SoC $_{\text {DESS_max }}$ are limited to $20 \%$ and $80 \%$, respectively. The battery's SoC was limited to $20-80 \%$, at which the battery is most efficient $[46,47]$. Therefore, the mode is changed based on the electricity generated by PV and the battery state, and the size of the charge/discharge current of the DESS is determined at this time. IDESS_discharge* is the target discharge current of the battery, and IDESS_scharge* is the target charge current. The battery of the DESS can be charged by PV and the MESS. IMESS_discharge_ref is the target current required to charge the DESS using the MESS. 
When the DESS receives the operation signal of the MESS from each mode to perform the auxiliary role of $\mathrm{PV}$, it determines the amount of charge/discharge depending on the state of PV. PV performs MPPT control, which is further involved in charging and discharging, depending on the PV output state based on the SoC. The operation algorithm of the PV-DESS integrated module operates in four main modes.

\subsubsection{PV-DESS Operation Mode A}

In the case where the PV output has not decreased because no insolation drop occurs, the PV module alone operates, whereas, for a constant output of the PV-DESS integrated module, the connected DESS does not operate.

\subsubsection{PV-DESS Operation Mode B}

In the case where discharging can be performed based on the SoC of the DESS because the PV output has decreased due to an insolation drop, the connected DESS operates to maintain constant power of the PV-DESS integrated module.

\subsubsection{PV-DESS Operation Mode C}

Mode $C$ operates under two situations. The first is where the output of PV decreases, and the associated DESS must operate while the DESS cannot perform discharging because the SoC of the DESS is low. The second is where an operation signal to charge the DESS has been received from the EMS of the MESS in a period where PV power generation is not available. In the latter case, the charging of the DESS operates with the charging current reference received from the EMS of the MESS.

\subsubsection{PV-DESS Operation Mode D}

If $\mathrm{PV}$ can no longer generate electricity, mode $\mathrm{D}$ is activated. It can be determined by the SoC of the DESS. If the SoC of the DESS is no longer dischargeable, mode $C$ is activated. If the $\mathrm{SoC}$ of the DESS is dischargeable, the discharge current reference received from the EMS of the MESS is compared to the dischargeable current considering the DESS's SoC, and then the final discharge current reference is determined. The PV operates based on the determined discharge current reference.

Figure 3 presents the power flow diagram of the PV-DESS integrated module proposed in this paper. The proposed module outputs constant power of the DC MG and compensates for the shortcomings of the intermittent power source of PV.

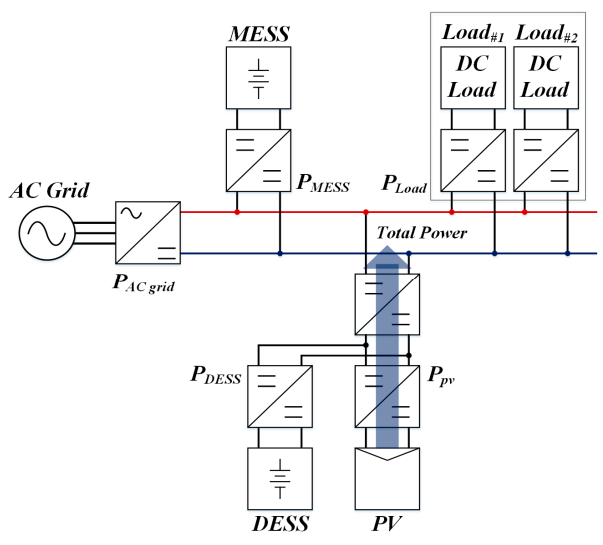

(a)

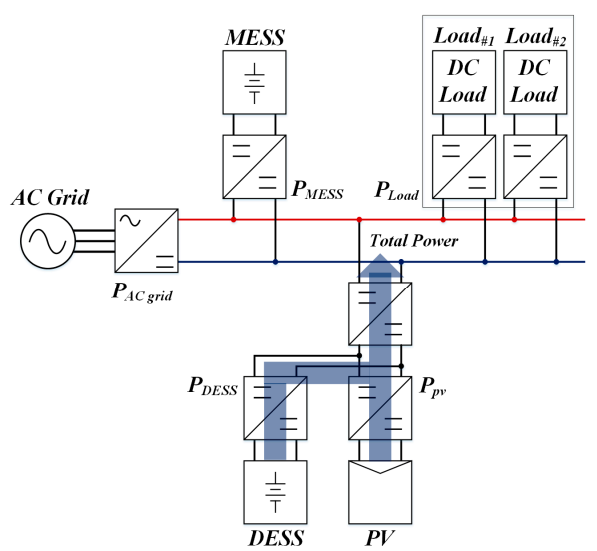

(b)

Figure 3. Cont. 


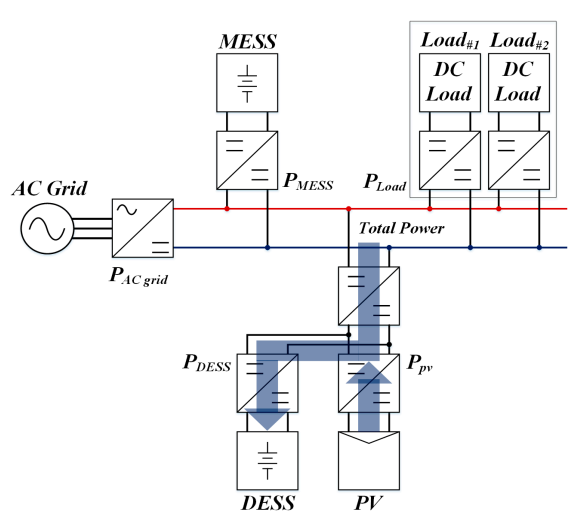

(c)

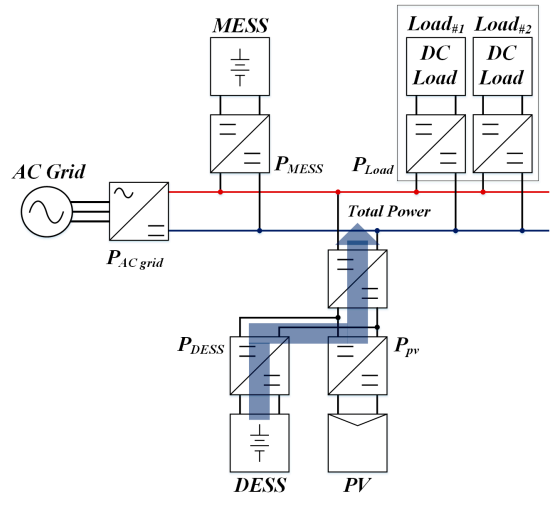

(d)

Figure 3. Power flow diagram of the PV-DESS integrated module: (a) PV-DESS operation mode A, (b) PV-DESS operation mode B, (c) PV-DESS operation mode C, and (d) PV-DESS operation mode D.

\subsection{MESS Algorithm with High Efficiency at Light Load}

Typically, power conversion devices have significantly lower efficiency at light load. PCSs operate as a bidirectional converter, showing similar efficiencies in the buck and boost modes. Thus, a PCS shows inherent efficiency characteristics, as well as low efficiency under light load conditions. PCSs constituting ESSs are used with large capacities when designing and manufacturing systems. PCSs designed for large capacities also exhibit very similar efficiency characteristics. Thus, regardless of the capacity of the PCSs, their efficiency characteristics are very similar $[9,10]$. The ESS determines the operation mode based on the SoC of the battery. The magnitude of the charge/discharge current in the battery is determined by the preceding determined operation mode and the SoC of the battery. When the capacity of the battery is significantly higher than that of the PCS, a significantly shorter time is consumed for a light load condition. However, when the capacity of the PCS is high, the efficiency of the ESS is lowered because the time for the occurrence of the light load condition is prolonged. This reduction in efficiency requires a longer time for the charging of the battery, and it may occasionally fail to satisfy the power required by the load during discharge. Thus, an MESS requires high efficiency in all sections.

The PCS of the ESS is divided into a single PCS and a modular PCS. The former has the advantages of a simple system configuration and high maximum efficiency; the latter can achieve high efficiency in all sections by adjusting the number of PCS modules, depending on the output of the ESS.

A typical modular PCS operates by uniformly sharing a certain amount of power. In this method, it is easy to increase the capacity, because the control is simple, depending on the increase in the number of modules. However, it has efficiency characteristics similar to a system composed of a single PCS. Thus, its efficiency curve has the same problem as a single PCS, with low efficiency at light load.

This section describes the algorithm with high efficiency under light load for the modular PCS.

Figure 4 shows the efficiency characteristics depending on capacity and the PCS module control. The modular PCS constitutes a system that uses several single PCSs with small capacity. The modular PCS, which performs the load share function, is easy to control by allowing each module to control the same output, and the capacity of the ESS can be raised by simply adjusting the number of modules according to the increase in battery capacity. However, above a certain load, the efficiency increases. The maximum efficiency tracking PCS performs control to ensure operation at maximum efficiency. 


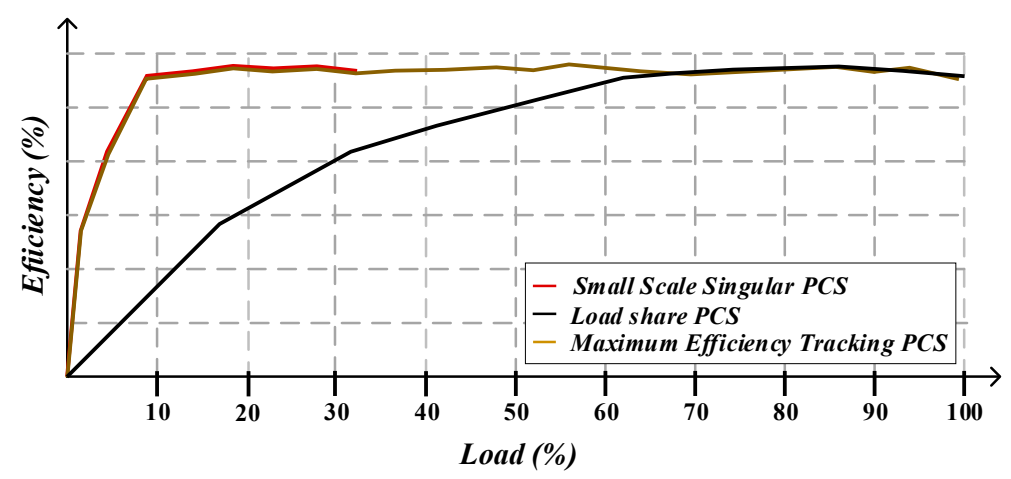

Figure 4. Efficiency characteristics depending on the PCS capacity and module control.

Figure 4 shows the efficiency characteristics of the PCS that performs the load share function. By equating the load sharing ratio between PCSs, the deviation between them is minimized. There is no temperature deviation between PCSs in this operation method. Equation (1) is a formula for the efficiency curve of the PCS performing the load sharing function. Despite an error in the efficiency due to the parasitic component of the PCS, the PCS can be regarded as the same from $\eta_{1}$ to $\eta_{N}$.

$$
\begin{aligned}
& P_{\text {Load_share_out }}=\frac{P_{\text {Load_share } i n}\left(\eta_{1}+\cdots+\eta_{N}\right)}{P C S_{N}} \\
& \eta_{\text {Load_share }}=1-\frac{P_{\text {Load_share_out }}}{P_{\text {Load_share_in }}}
\end{aligned}
$$

where

$P C S_{N}=$ the number of PCS modules;

$\eta_{N}=$ efficiency of the last module.

The PCS performing the load sharing function shows a constant output in all modules. Thus, it can have high efficiency from a certain area. However, the MESS operates in a wide range of load areas, depending on the load state and on the generation state of renewable energies. In this respect, the MESS must have high efficiency whether under light, heavy, or rated load, which is a means of increasing the energy efficiency of the DC MG.

Equation (2) is a formula for the efficiency curve of the PCS that produces the maximum efficiency. Assuming that the efficiency of the PCS is the same as that of the parasitic component excluded, the efficiency is determined according to the input power of each PCS. Thus, the efficiency is determined by how the input power is divided and controlled:

$$
\begin{aligned}
& P_{M E T \_o u t}=P_{M E T \_i n \_1} \cdot \eta_{1}+P_{M E T \_i n \_2} \cdot \eta_{2}+\cdots+P_{M E T \_i n \_N} \cdot \eta_{N} \\
& \eta_{M E T}=1-\frac{P_{M E T \_o u t}}{P_{M E T \_i n \_1}+\ldots+P_{M E T \_i n \_N}}
\end{aligned}
$$

Figure 5 shows the proposed algorithm to ensure that the PCS operates with maximum efficiency. The power control of a DC MG is determined through the EMS. The EMS also determines the charge/discharge mode of the MESS, as well as the magnitude of the current. These modes and the magnitude of the current are utilized to select the maximum number of modules of the PCS. Furthermore, the temperature of all PCSs is measured before PCS operation, to determine whether there is any abnormality. The appropriate temperature for the PCS was selected to be $20-80^{\circ} \mathrm{C}$. The rated capacity of the PCS in one module is $6.6 \mathrm{~kW}$. However, the maximum efficiencies and rated capacities of many PCSs are different. Although the number of modules is determined based on the rated capacity of the PCS, these modules do not reach this rated capacity. Thus, after one module operates up to its maximum efficiency point, the next module is operated. After the maximum number of modules operate at maximum efficiency, they reach the rated capacity through load sharing. 


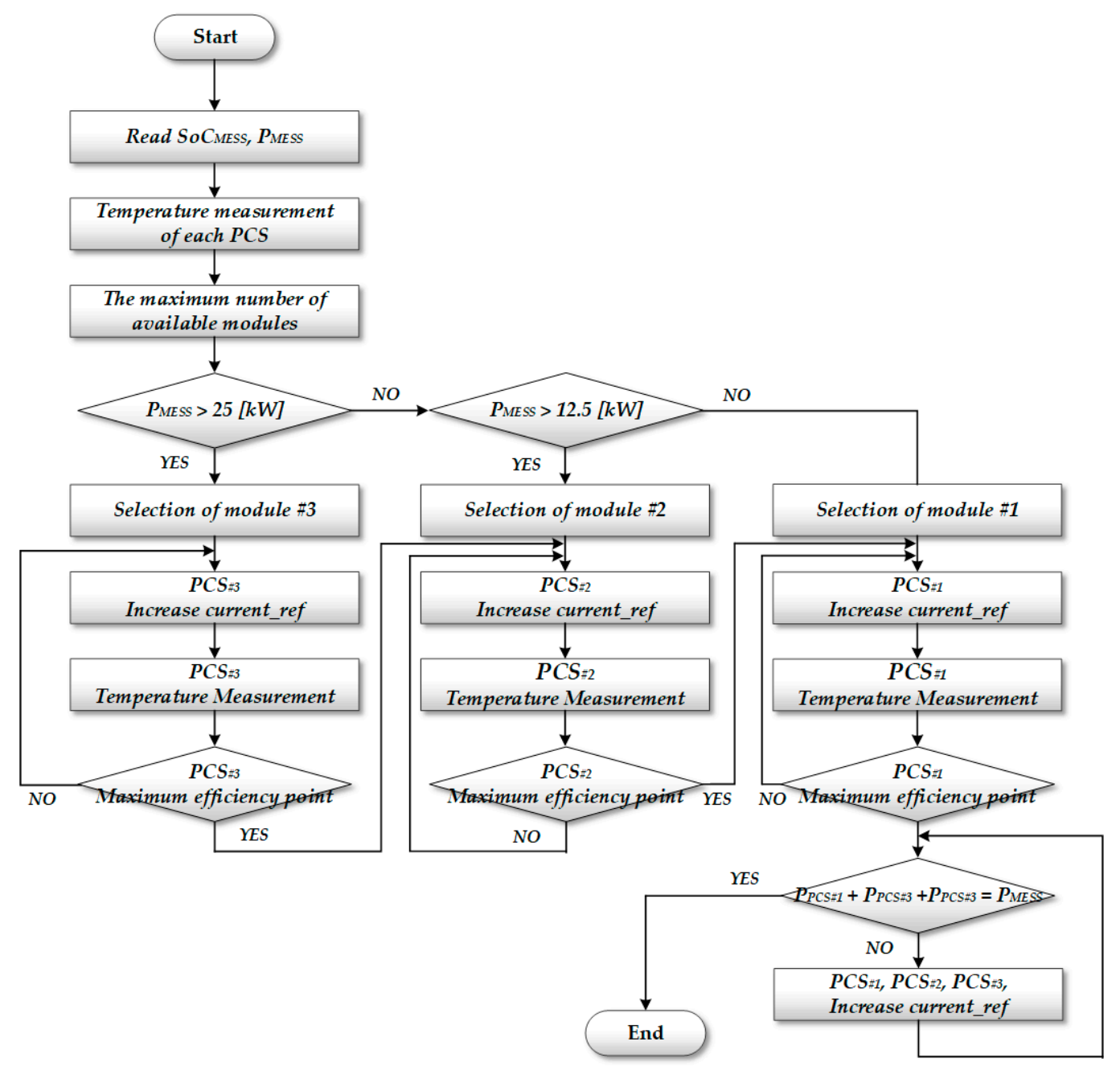

Figure 5. Charging/discharging mode algorithm at maximum efficiency.

Most of the MESSs are designed with large capacity. When configuring a modular PCS, the smaller the module capacity, the higher the number of PCSs used. For when multiple PCSs are used and one module fails, a system can be designed to enable the operation of the MESS through the fault diagnosis algorithm. Moreover, the maximum efficiency point can be advanced through the algorithm proposed in this paper. There is a high likelihood that multiple loads and RESs would be additionally installed for a DC MG. Thus, an algorithm that can operate with maximum efficiency by utilizing a modular PCS capable of responding to various states is required.

\section{Algorithm for Efficient Energy Management of Microgrids}

The energy flexibility of an MG is determined by the EMS algorithm. The EMS manages the control system, load management system, and energy management system of the MG. The EMS of the MG manages energy flexibly. In addition, there is a gridconnected mode to improve the insufficient energy state of the MG and the reliability of the system. The MG can reduce the system operating costs through the grid-connected mode, necessitating flexible energy management.

PV has a fixed time period for power generation. Typically, the time period when PV is generated tends to be under high load of the AC grid. Thus, the EMS should increase the utilization rate of RESs and lower the utilization rate of the AC grid.

Figure 6 shows the EMS algorithm proposed in this paper, which always operates for the energy management of the MG. Several PCSs of the MG configured in this paper were designed and manufactured within the range not exceeding the maximum temperature of 
$80{ }^{\circ} \mathrm{C}$. Thus, this algorithm is terminated by determining the state exceeding the maximum temperature as a failure.

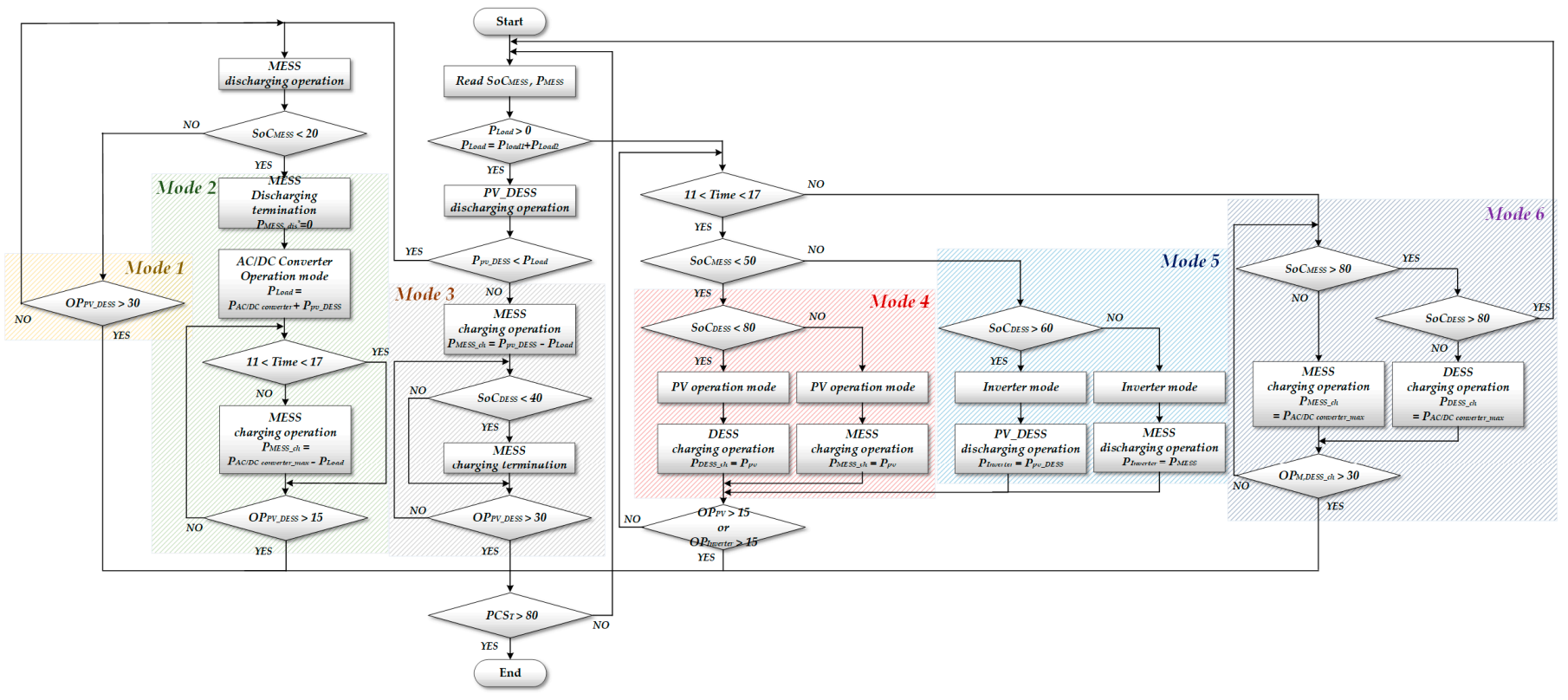

Figure 6. EMS operation algorithm for efficient energy management.

The algorithm proposed in this paper has different voltage control priorities, depending on various states. When the load is connected, the priority of voltage control is primarily given to the PV-DESS. A typical PV is an energy source that induces high voltage fluctuations, which is unsuitable for controlling the voltage of an MG. However, PV-DESS can perform the voltage control of the MG through control and design with the goal of constant output.

The purposes of algorithms for energy management differ depending on the connection state of the load. In a state where the load is not connected, each battery is charged and converted to an inverter mode. ESSs can manage surplus power. Thus, an ESS can be linked to many new energy sources, including RESs. However, there is a limit to charging the ESS with these RESs alone. Thus, the AC/DC converter is used to compensate for the insufficient energy. An AC/DC converter uses the AC_Grid, which is typical, and its costs accumulate over time. This cost is related to the operating cost of the DC MG. Typically, the time period during which PV can generate power and the time period when electricity rates are high tend to be similar. In this case, the operating cost of the MG is minimized by supplying power to the AC_Grid using PV and the MESS. In addition, the smooth operation of the DC MG can be secured by charging the energy of the MESS and DESS at the time period when the electricity rate is low.

When a load is connected, the priority of voltage control is given to the PV-DESS. The power generation of the PV-DESS and that of the load are compared. If the former is higher than the latter, the remaining surplus power is charged to the MESS. If the battery SoC of the DESS is less than $40 \%$, the charging of the MESS is paused, and power is supplied to the load alone. Second, if the power generation of the PV-DESS is lower than that of the load, another PCS is utilized to supply insufficient power. The MESS is primarily used to supply the power, and it operates up to at least $20 \%$ of the SoC. The usage range of $20-80 \%$ for the $\mathrm{SoC}$ was selected for the MESS. This setting has commonly been used for ESSs installed indoors, and $10-90 \%$ is common for ESSs outdoors.

The operation mode of a DC MG is determined based on various situations. Because this paper utilizes PV (an intermittent energy source) in combination with the DESS, it has the advantage of constantly controlling the voltage of the MG. This constant control of 
voltage is beneficial, in that it is possible to reduce the AC grid electricity consumption and cost by increasing the use of RESs.

The EMS algorithm proposed in this paper is intended for efficient energy management by applying the constant power tracking algorithm of the integrated PV-DESS module (Section 2.1) and the MESS algorithm with high efficiency at light load (Section 2.2).

The proposed EMS algorithm can be divided into six categories. Modes 1-3 are in the state where the load is connected, and the voltage control of the MG is performed by using PV-DESS. Modes 4-6 are in the state where there is no load, and each battery is charged using a PV or AC/DC converter and converted to an inverter mode. Figure 7 shows a power flow diagram for each mode of the EMS.

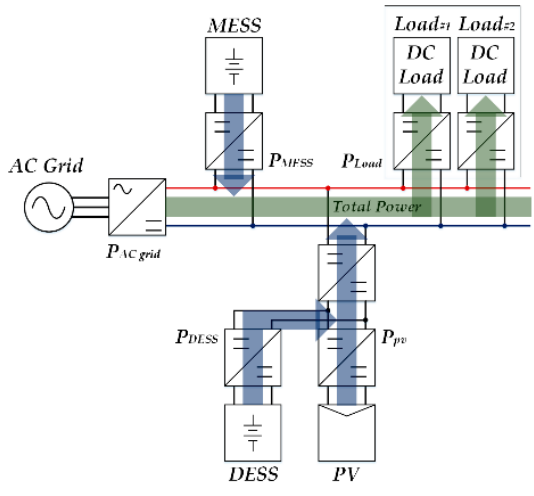

(a)

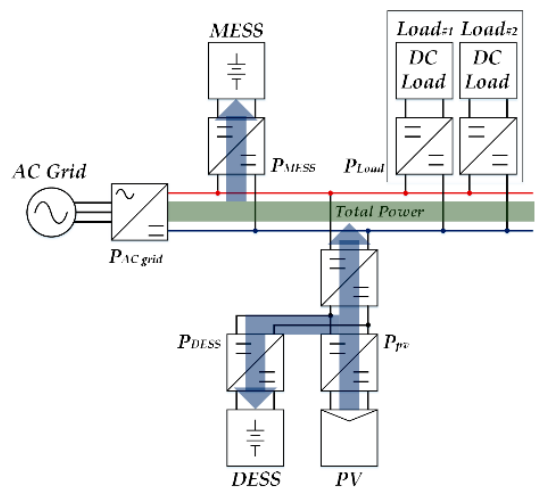

(d)

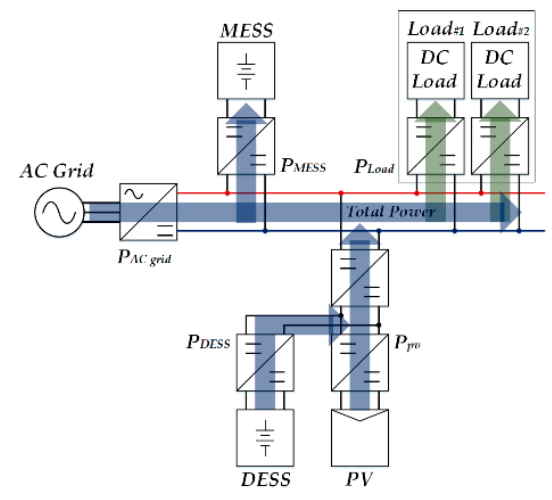

(b)

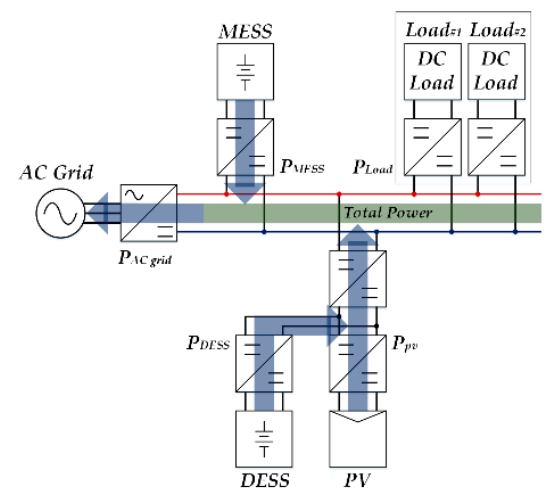

(e)

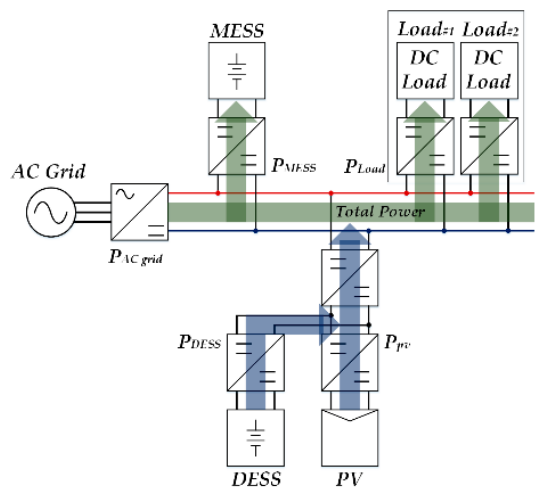

(c)

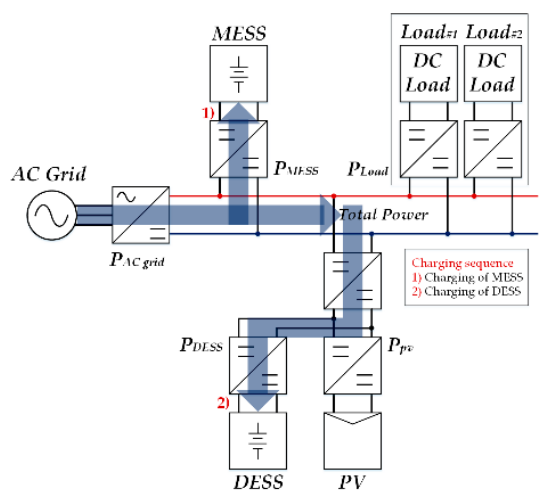

(f)

Figure 7. Power flow diagram of MESS: (a) EMS mode 1, (b) EMS mode 2, (c) EMS mode 3, (d) EMS mode 4, (e) EMS mode 5, and (f) EMS mode 6.

Each mode of the EMS is determined by the battery state of the MESS and the required load energy. Thus, the battery state of the MESS (SoC ${ }_{\text {MESS }}$ ) is received, and the power generation of $P_{\text {MESS }}$ after each mode operation is checked. Because two different loads were used in this study, the amount of electricity required for $P_{\text {load1 }}$ and $P_{\text {load2 }}$ was measured. $\mathrm{PV}$ is an intermittent energy source with a fixed generation time. In this study, PV-DESS supplied a constant amount of electricity, allowing for a stable power supply to loads. Therefore, the PV-DESS module power generation, expressed as $\mathrm{P}_{\mathrm{pv} \_ \text {DESS, }}$ was measured. $\mathrm{OP}_{\mathrm{PV} \_D E S S}$ is the operation time of the PV-DESS's stable power supply mode, while $\mathrm{OP}_{\mathrm{PV}}$ refers to the operation time of the PV single operation mode. The operation time of the inverter mode that operates using the electricity of the DESS or MESS can also be checked with $\mathrm{OP}_{\text {Inverter. }}$ To ensure the stable operation of the $\mathrm{MG}$ during the low consumption

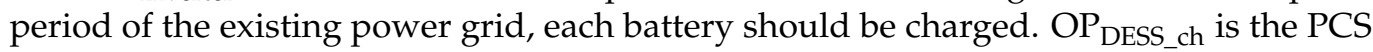
operation time during battery charging. 
There are several PCSs in an MG. Following the completion of each PCS operation, the temperature of each PCS is measured to detect PCS failure. If the temperature of a PCS $\left(\mathrm{PCS}_{\mathrm{T}}\right)$ exceeds $80^{\circ} \mathrm{C}$, this is considered a PCS failure and the EMS is shut down.

\subsection{EMS Mode 1}

In mode 1, power is supplied to the load using the PV-DESS and MESS. This section is operated when the SoC of the MESS is $20 \%$ or more, and the SoC of the DESS is $30 \%$ or more. The DESS ensures a stable PV output. Therefore, the DESS is set to operate in the range of $20-30 \%$.

\subsection{EMS Mode 2}

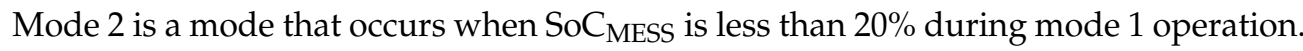
The power is supplied to the load using the PV and AC/DC converter. Typically, the electricity rates of an AC_Grid vary, based on time sections. The time period 11:00-17:00 corresponds to the maximum load section, where the maximum electricity rate occurs. Thus, the MESS is charged, and power is supplied to the load by utilizing the AC/DC converter and PV-DESS in other time periods. PMESS_ch_ref (i.e., charging power for MESS) can be charged as much as the difference between $\mathrm{P}_{\mathrm{AC} / \mathrm{DC} \text { _converter_max }}$ (the maximum capacity of the AC/DC converter) and $\mathrm{P}_{\text {Load }}$. After 15 min of continuous operation using the $\mathrm{AC} / \mathrm{DC}$ converter, the time section is further determined.

\subsection{EMS Mode 3}

Mode 3 occurs for a section where power is supplied to the load and MESS by using the PV-DESS. It provides a stable power supply to the load, and it charges the surplus power with the MESS. The DESS serves to supplement the insufficient power generation of PV. Thus, to track the constant power of the PV-DESS, the SoC limit of the DESS was raised to $40 \%$. The following is the mode selection when no load is connected. In this state, the time period when the AC_Grid's electricity rate is high is selected.

\subsection{EMS Mode 4}

Mode 4 corresponds to the time section when PV can generate power and when $\mathrm{SoC}_{\mathrm{MESS}}$ is less than $50 \%$. Mode 4 is the mode for charging each battery. When the battery SoC of the DESS is less than $80 \%$, the DESS is charged. To primarily charge the DESS using $\mathrm{PV}, \mathrm{SoC}_{\mathrm{DESS}}$ was selected as $80 \%$. Mode 4 corresponds to the time period with the highest power usage. Thus, it is necessary to prepare for a stable power supply to the load. An MESS tends to be installed with large capacity compared to PV. Thus, the DESS is primarily charged to prepare for the stable operation of the PV-DESS's constant power tracking.

\subsection{EMS Mode 5}

Mode 5 corresponds to the conversion to an inverter mode. DC MGs can be linked to several RESs. However, the DG or AC/DC converters are utilized to secure system reliability. In the present work, the system was configured using an AC/DC converter. Thus, when charging the battery, the AC_Grid's electricity rate occurs, and mode 5 is converted to an inverter mode to reduce the cost. The inverter mode operates only when the AC_Grid's electricity rate is the lowest. The voltage control priority of the MG is given to the PV-DESS. The voltage control of the PV-DESS is up to $40 \%$ of $S O C_{\text {DESS, }}$ and then the voltage control of the MESS is performed.

\subsection{EMS Mode 6}

In mode 6, each battery is charged by using the AC_Grid. The MESS is designed and installed with the largest capacity among the PCSs of the MG. Thus, a significantly long time is required to fully charge the MESS. After the MESS is fully charged, the DESS is further charged. 


\section{Experiment Results}

Figure 8 shows how $\mathrm{H} / \mathrm{W}$ was configured to verify the operation algorithms of each PCS, as well as the MG, proposed in this paper.

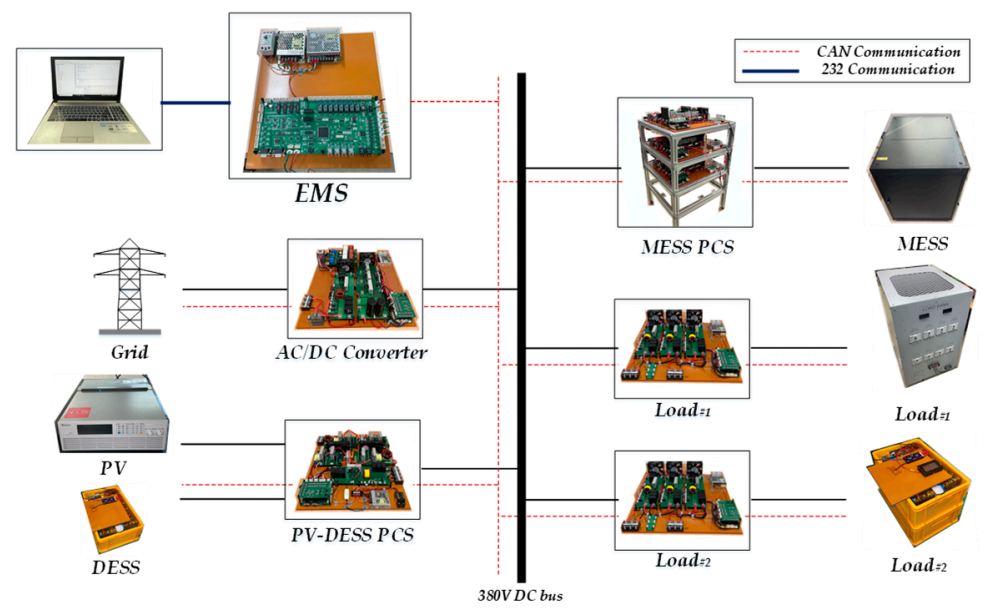

Figure 8. Proposed configuration of the DC MG hardware.

A resistive load and a battery load were utilized for each load. The resistance load was $0.7-13 \mathrm{~kW}$, for which a variable resistor was used, and the battery load was designed to be $48 \mathrm{~V}$ and $105 \mathrm{Ah}$.

Table 1 shows the PCS module specifications of the MESS. This paper proposes an operation algorithm with high efficiency for a light load of the MESS. The battery of the MESS consisted of a 120-unit LiFePO4 (3.2-3.7 V) in series. The battery voltage was 384-444 V with $125 \mathrm{Ah}$ and $55 \mathrm{kWh}$.

Table 1. MESS battery capacity and PCS 1 module specification.

\begin{tabular}{cccc}
\hline Parameters & Value (Unit) & Parameters & Value (Unit) \\
\hline \multirow{2}{*}{ MESS battery } & $384-444(\mathrm{~V})$ & Output current $(\max )$ & $32.6(\mathrm{~A})$ \\
& $125(\mathrm{Ah})$ & Switching frequency & $150(\mathrm{kHz})$ \\
$\mathrm{V}_{\text {dc_bus }}$ & $380(\mathrm{~V})$ & Buck-boost converter & C3M0025065D \\
& & Power device & $25(\mathrm{~m} \Omega)$ \\
\hline
\end{tabular}

The PCS 1 module specifications for the MESS were composed of three parallel PCS modules of $12.5 \mathrm{~kW}$ with a maximum current of $32.6 \mathrm{~A}$. The charging and discharging of the battery were performed with a $0.8 \mathrm{C}$ rate or less.

Table 2 shows the efficiency measurement depending on the mode of one PCS module. The battery charging mode of the MESS is the boost mode, and the discharging mode is the buck mode. Typically, the power conversion device shows a decrease in efficiency at the rated load. Therefore, the next PCS is operated before the decrease in efficiency appears. The number of modules is sequentially raised, and when the maximum number is reached, the capacity is gradually raised to reach the target amount of power. 
Table 2. Measurement of MESS PCS 1 module efficiency.

\begin{tabular}{ccc}
\hline \multirow{2}{*}{ Load (\% of $\mathbf{1 2 . 5} \mathbf{k W})$ [\%] } & \multicolumn{2}{c}{ Efficiency $\mathbf{( \% )}$} \\
\cline { 2 - 3 } & Boost Mode & Buck Mode \\
\hline 5 & 80 & 83 \\
10 & 92.38 & 91.51 \\
20 & 95.23 & 94.33 \\
30 & 96.15 & 95.57 \\
40 & 96.32 & 96.34 \\
50 & 96.35 & 96.33 \\
60 & 96.53 & 95.86 \\
70 & 96.3 & 95.51 \\
80 & 96.1 & 95.13 \\
90 & 94.8 & 95.23 \\
100 & 93.55 & 94.5 \\
\hline
\end{tabular}

Figure 9 compares the efficiency measurements depending on the operation algorithm of the MESS. To verify the validity of the algorithm with high efficiency at light load, as proposed in this paper, the efficiency of a single $37.5 \mathrm{~kW}$ capacity PCS, that of a threemodule PCS, to which the load share algorithm was applied, and that of a three-module PCS, to which the algorithm proposed in this paper was applied, were compared.

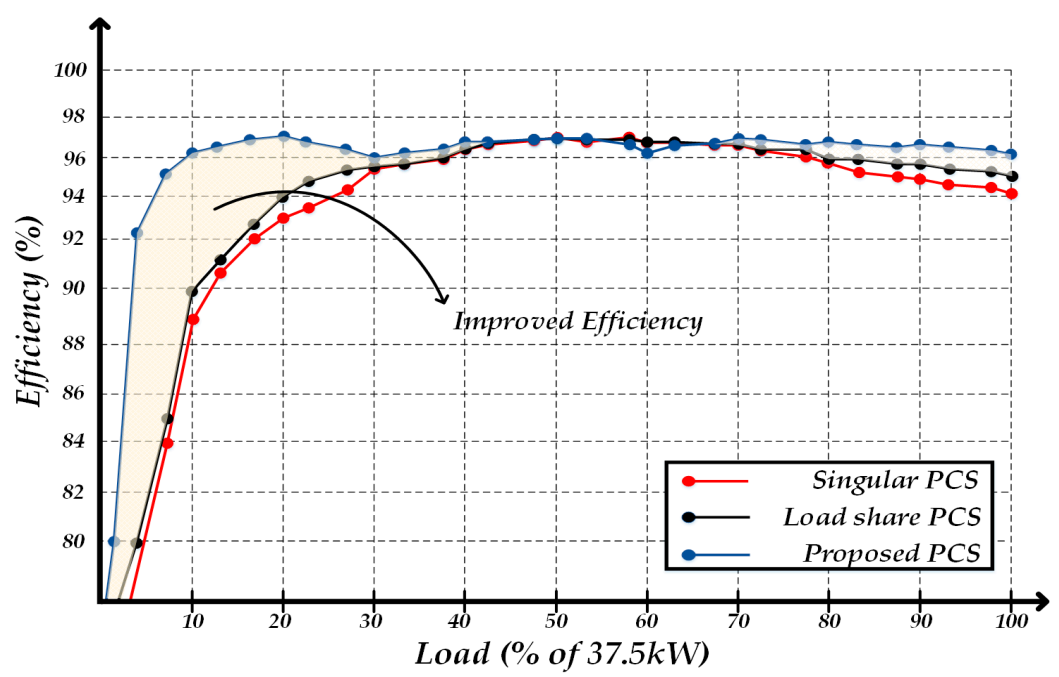

Figure 9. Efficiency measurement depending on the MESS PCS operation method.

The same H/W was used for the load share and for the proposed PCS. However, the efficiency differed depending on the operation method of the module. The MESS operation algorithm proposed in this paper had an efficiency value of $92.38 \%$ from a load factor of $3 \%(1250 \mathrm{~W})$. In addition, this efficiency value reached $96 \%$ when the load factor was $10 \%$ or more.

The PCS 1 module constituting the MESS had a capacity of $12.5 \mathrm{~kW}$. However, the reduction in efficiency occurred above the $60 \%$ load section. Thus, the next module operated from $7.5 \mathrm{~kW}$ of the preceding PCS.

Figure 10 shows the waveform of charging the battery using the PCS of the MESS. Figure 10a shows the waveform of charging the battery with a light load, while Figure 10b shows the waveform of charging the battery with the maximum current. 


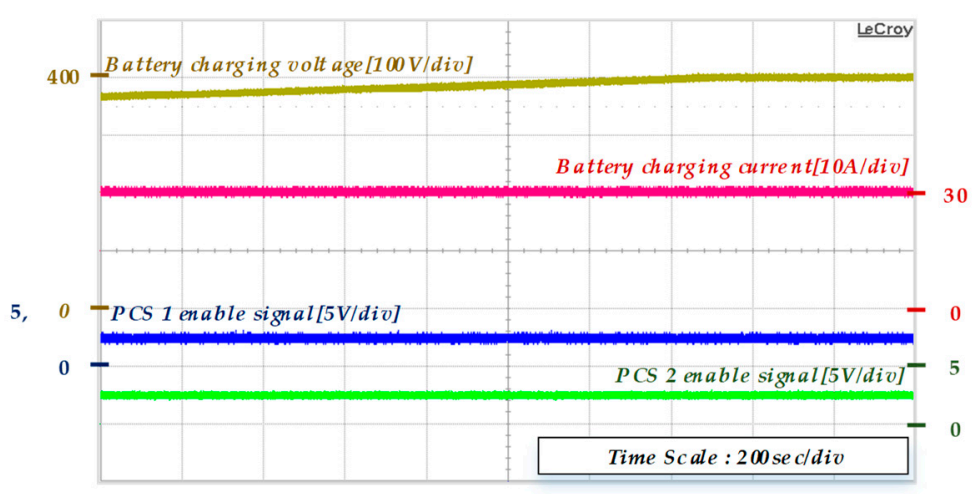

(a)

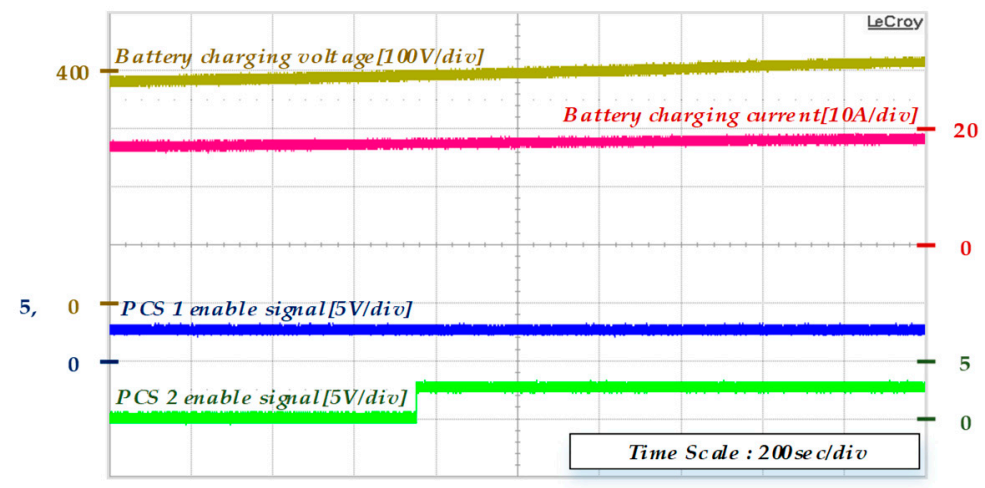

(b)

Figure 10. Battery charging waveform of the MESS: (a) operation under a light load condition and (b) operation under a rated load condition.

During light load operation, one or two PCSs are selected and operated, depending on the PCS efficiency characteristics. The rated operation is performed in the same manner as that in the load share of the PCS. After the operation of three PCSs at maximum efficiency, the insufficient power is redressed by sharing the same amount of power.

For the verification of the constant power tracking algorithm of the PV-DESS, which was designed to be $4.89 \mathrm{kWh}$ at $60 \mathrm{Ah}$, 21-unit LiFePO4 batteries were used. Moreover, each PCS utilized a boost converter for MPPT control PV at $5 \mathrm{~kW}$ and DAB for insulation from the MESS.

DAB 1 was connected to the DESS and PV, and DAB 2 was connected to DAB 1 and the MG's power distribution network voltage. Table 3 shows the specifications of the batteries used in the PV-DESS and each PCS. PV-DESS consisted of two stages. Thus, the PV and DESS were boosted to $180 \mathrm{~V}$, and further to $380 \mathrm{~V}$ (i.e., the MG distribution network voltage) by utilizing DAB 2 . 
Table 3. PV-DESS battery capacity and PCS 1 module specification.

\begin{tabular}{cccc}
\hline Parameters & Value (Unit) & Parameters & Value (Unit) \\
\hline DESS battery & $67.2-77.7(\mathrm{~V})$ & PV voltage at MPP, & $140(\mathrm{~V})$ \\
DESS PCS & $80(\mathrm{Ah})$ & PV current at MPP & $35.7(\mathrm{~A})$ \\
Maximum power output & $5(\mathrm{~kW})$ & PV boost converter & $5(\mathrm{~kW})$ \\
Transformer turn ratio & $1: 2.5$ & Maximum power output & PV PCS inductance \\
Leakage inductance & $2.5(\mu \mathrm{H})$ & PV PCS switching frequency & $60(\mathrm{kHz})$ \\
DAB switching frequency & $100(\mathrm{kHz})$ & PV, DESS PCS & $\mathrm{C} 3 \mathrm{M} 0025065 \mathrm{D}$ \\
& & Power device & $(25 \mathrm{~m} \Omega)$ \\
\hline
\end{tabular}

Figure 11 shows the output voltage, current, and power waveforms of PV when no insolation drop occurs. When an insolation drop occurs, mode B operates to compensate for the intermittent characteristics.

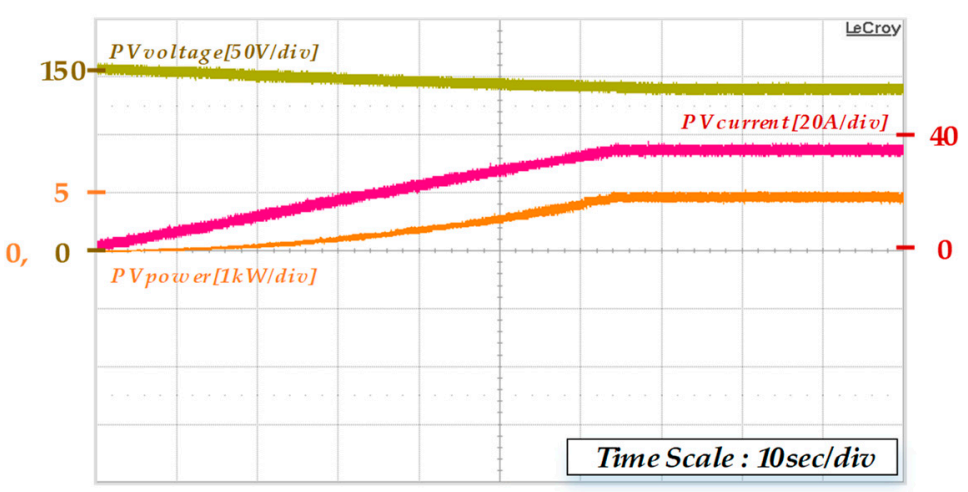

Figure 11. PV voltage, current, and power waveforms for checking PV operation.

VPV-MPP of $140 \mathrm{~V}$ and IPV-MPP of $35.7 \mathrm{~A}$, which are the maximum power points (MPP) of PV, were identified, and the independent operation of PV was verified through experiments.

To verify the constant power tracking algorithm, the DESS of the PV-DESS integrated module was verified. As shown in Figure 12a, (1) when there is no insolation drop, the DESS does not operate due to mode A operation; (2) an insolation drop activates mode B, which is supported by the DESS; and (3) mode D is verified, in which the DESS supplies power when the SoC of the DESS is sufficient, because the PV can no longer operate. As shown in Figure 12b, which is the same as shown in Figure 12a, PV enters the charging mode, mode $C$, while operating with reduced PV output, and it receives the PV output and power from the distribution network to perform charging. If the PV does not operate, then the PV will perform charging by receiving power from the power distribution network alone.

Figure 13 shows power generation vs. time. The amount of electricity by time represents the mean power generation for $1 \mathrm{~h}$; however, the actual power generation varies in real time. This is linked to the DC distribution network of the MG, causing changes in the voltage of the DC distribution network. 


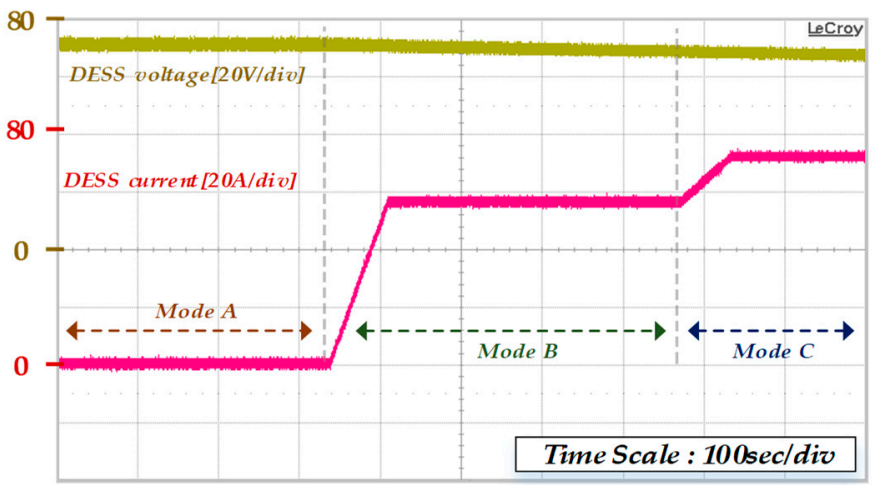

(a)

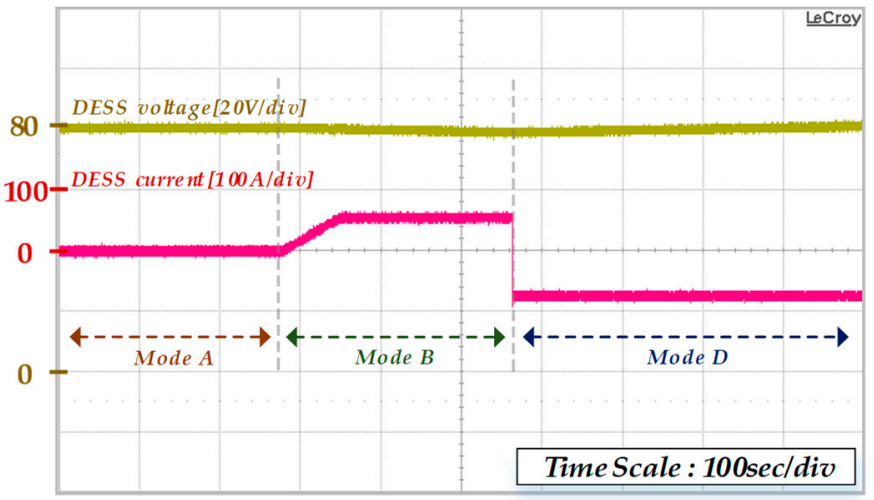

(b)

Figure 12. Experimental results on the DESS to compensate for the intermittent characteristics of PV (a) when the SoC of the DESS is sufficient and (b) when PV does not operate due to the smaller SoC of the DESS than the range.

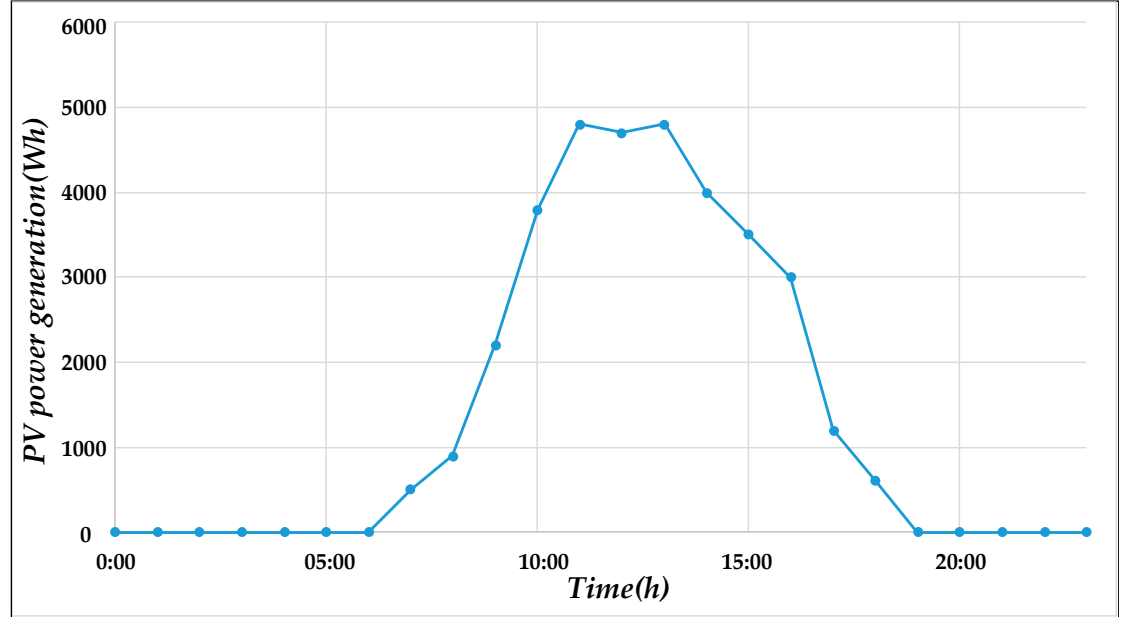

Figure 13. Amount of power generated by solar power over time.

Table 4 shows the power generation measured every 10 min between 10:00 and 11:00 and between 14:00 and 15:00. In this study, the DESS operates as a device to maintain maximum PV power generation. With the changing solar radiation, the PV power generation gradually increases and then declines after reaching its peak. The power generation can also decrease by partial shading. The DESS is input when the power generation is lower than that of the previous $10 \mathrm{~min}$ (to supply the same amount of power as before). Table 5 shows the ESS discharge current based on PV power generation. Because the DESS plays 
the role of compensating for the maximum PV output, it generates the maximum electricity of the previous time.

Table 4. The amount of electricity measured in ten-minute units of solar power generation.

\begin{tabular}{cc}
\hline Time(h) & PV Power Generation $\mathbf{( W h )}$ \\
\hline $10: 00-10: 10$ & 3150 \\
$10: 10-10: 20$ & 3250 \\
$10: 20-10: 30$ & 3754 \\
$10: 30-10: 40$ & 4046 \\
$10: 40-10: 50$ & 4215 \\
$10: 50-11: 00$ & 4314 \\
$14: 00-14: 10$ & 4620 \\
$14: 10-14: 20$ & 4300 \\
$14: 20-14: 30$ & 4000 \\
$14: 30-14: 40$ & 3900 \\
$14: 40-14: 50$ & 3850 \\
$14: 50-15: 00$ & 3600 \\
\hline
\end{tabular}

Table 5. ESS discharge power according to the fluctuation of solar power generation.

\begin{tabular}{cccccc}
\hline & Case 1 & \multicolumn{3}{c}{ Case2 } \\
\hline $\begin{array}{c}\text { Number of } \\
\text { Experiments }\end{array}$ & $\begin{array}{c}\text { PV } \\
\text { Simulator } \\
(\mathbf{W h})\end{array}$ & $\begin{array}{c}\text { ESS Power } \\
\text { Generation } \\
\mathbf{( W h )}\end{array}$ & $\begin{array}{c}\text { Number of } \\
\text { Experiments }\end{array}$ & $\begin{array}{c}\text { PV } \\
\text { Simulator } \\
\text { (Wh) }\end{array}$ & $\begin{array}{c}\text { ESS Power } \\
\text { Generation } \\
\text { (Wh) }\end{array}$ \\
\hline 1 & 4600 & 0 & 1 & 3000 & 0 \\
2 & 4300 & 300 & 2 & 3100 & 0 \\
3 & 4000 & 600 & 3 & 3300 & 0 \\
4 & 3900 & 700 & 4 & 3600 & 0 \\
5 & 3850 & 750 & 5 & 3500 & 100 \\
6 & 3600 & 1000 & 6 & 3600 & 0 \\
\hline
\end{tabular}

For efficient energy management, the EMS algorithm to which the MESS algorithm and the PV-DESS integrated module algorithm were applied was verified through experiments.

Figure 14 shows the experimentally verified waveform of the EMS algorithm depending on the MESS, PV-DESS integrated module, and load. Figure 14a shows the waveforms experimented with for the low-SoC states of each battery in the MESS and DESS. The section operating in EMS mode 1 was in the state where the load of the MG was connected, and the power required by the load was $8 \mathrm{~kW}$. PV-DESS could output a total of $5 \mathrm{~kW}$. Thus, both the PV-DESS and MESS were utilized to supply power to the load. However, as the minimum SoC of the MESS was reached, it switched to EMS mode 2. The existing power grid was used to supply the amount of power that was insufficient due to the conversion to EMS mode 2 to the load. Moreover, power was supplied to the load, and the remaining surplus power was utilized to charge the battery. In EMS mode 6 conversion, the load of the MG was rejected, and the battery was charged by using the AC/DC converter.

Figure $14 \mathrm{~b}$ is the waveform for each mode conversion when the SoC of each battery in the MESS and DESS was high. The initial SoC of each battery was approximately $80 \%$, and the load during the initial operation was $3 \mathrm{~kW}$. PV-DESS outputted a total of $5 \mathrm{~kW}$. Thus, it operated at EMS mode 3, which supplied power to the load by using PV alone. Subsequently, if the load of the MG varied to $18 \mathrm{~kW}$ and the use of PV alone could not be sustained, it was converted to EMS mode 1, which supplied power to the load by utilizing the MESS and PV-DESS. Subsequently, when the load was rejected, the battery charge/discharge mode was determined depending on the SoC of each battery.

The time period during which PV operates and that when electricity rates are high are very similar. Thus, PV is utilized in this case. When the SoC of the DESS is less than $60 \%$, an inverter operation is performed by using the MESS. 


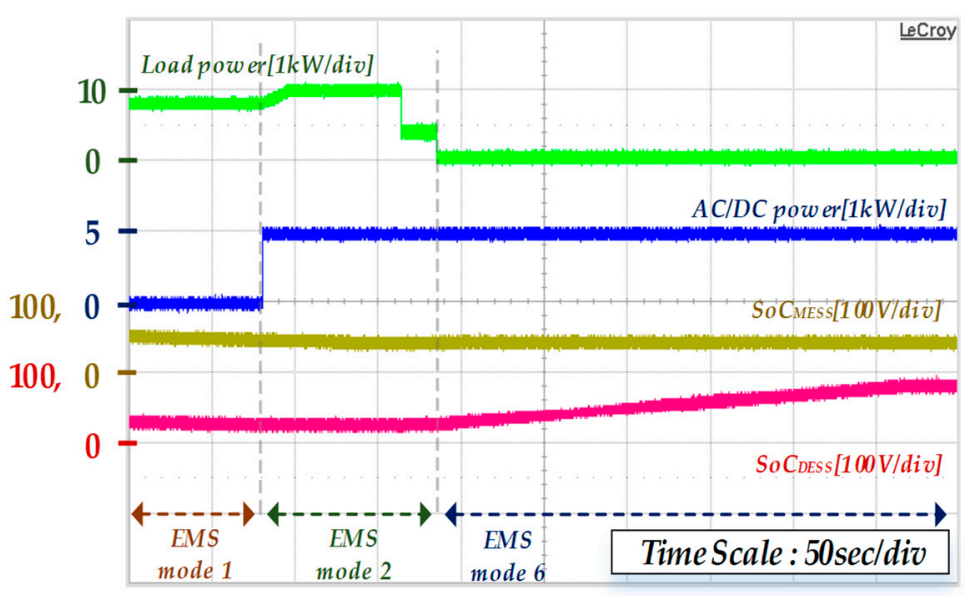

(a)

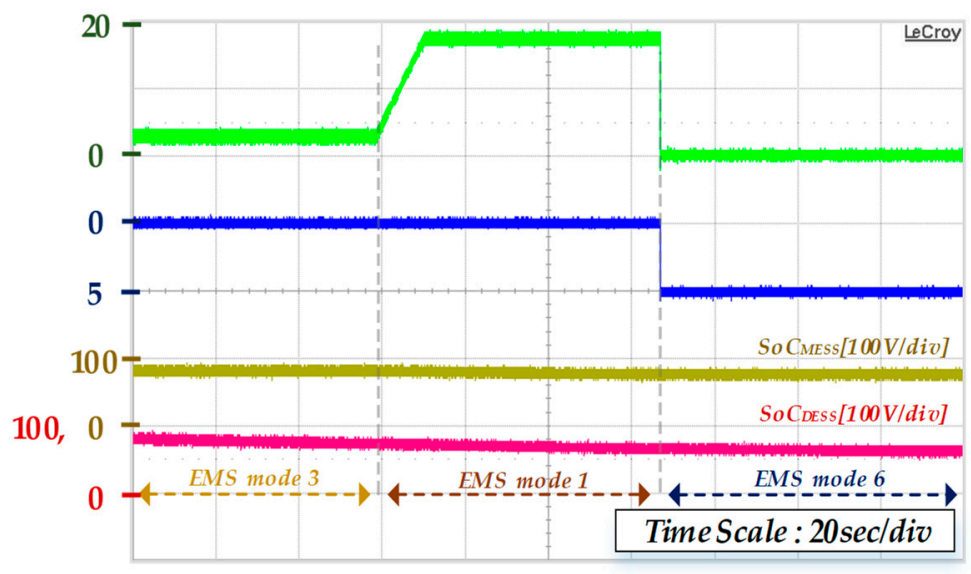

(b)

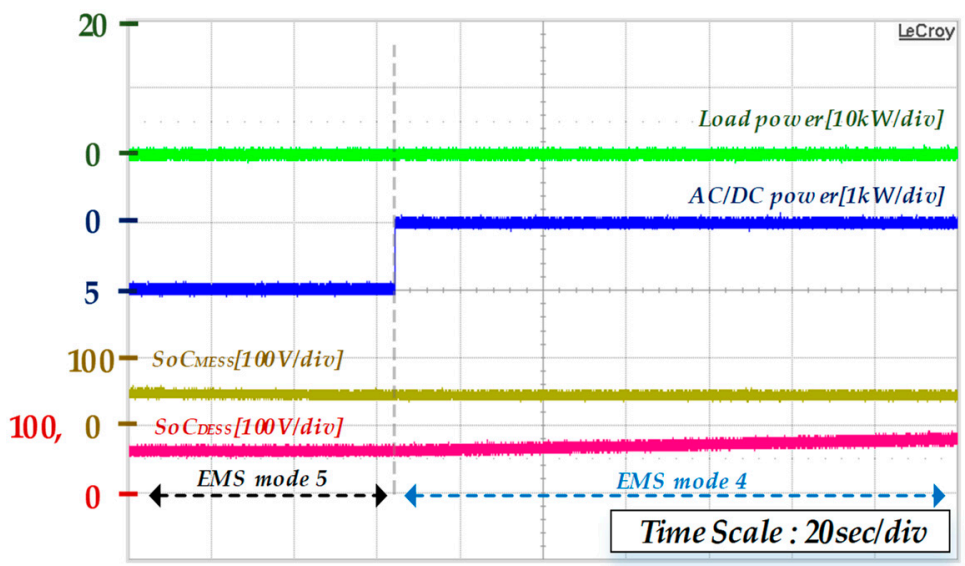

(c)

Figure 14. Experimental results for EMS algorithm for efficient energy management in a state where (a) the SoC of each battery of the MESS and DESS was low and (b) the SoC of each battery of the MESS and DESS was high. (c) The inverter operation and charging mode of each battery.

Figure 14c shows an inverter operation, as well as a charging mode for each battery; there was no load on the MG, the minimum SoC of the MESS battery was $50 \%$, and the battery SoC limit of the DESS was $60 \%$ at the time of an inverter operation. Thus, in this experiment, an inverter operation was performed by utilizing the MESS; when the minimum SoC of each battery was reached, the inverter operation (EMS mode 5) was 
terminated. In addition, in a state where PV could generate power under no load, each battery was charged by conversion to EMS mode 4. Compared to the battery of the MESS, PV has a significantly small capacity. Thus, a significantly long charging time is required. In EMS mode 4, PV was utilized to primarily charge the DESS and then the MESS.

\section{Conclusions}

This paper addresses the operation of each PCS for the efficient energy management of MGs. For efficient energy management, the disadvantages and problems of each PCS were supplemented.

First, to compensate for the intermittency of PV, this study proposes an operation algorithm for PV integrated with the DESS. To complement the intermittent characteristics of PV, the insufficient maximum PV power generation was compensated for based on the SoC of the DESS. An algorithm for operating the PV-DESS integrated module based on the solar radiation, the SoC of the MESS, and the SoC of the DESS was proposed and was verified through experiments.

Second, this study proposed an algorithm for tracking the maximum efficiency of the MESS in all areas. To realize highly efficient MESS in all areas, this paper proposes a control technique for achieving the same output for PCSs using the load share technique after maximum efficiency is reached. The proposed algorithm showed $92.38 \%$ efficiency from a load rate of $3 \%$ when operated with three modules, and an efficiency increase of $11-13 \%$ when the load share and singular techniques were compared.

This paper proposes an algorithm for efficient energy management, as well as an energy management system that compensates for the shortcomings of RESs. The proposed energy management system optimizes the energy flow of the MG, thereby increasing the utilization rate of RESs.

Author Contributions: Conceptualization, K.-S.N. and J.L.; Data curation, J.-M.K.; Formal analysis, K.-S.N. and J.L.; Project administration, C.-Y.W.; Software, J.-M.K. and Y.-S.L.; Writing—original draft, K.-S.N.; Writing - review and editing, J.Y. and C.-Y.W. All authors have read and agreed to the published version of the manuscript.

Funding: This research was funded by the National Research Foundation of Korea (no. 2019R1A2C2007216).

Acknowledgments: This work was supported by a National Research Foundation of Korea (NRF) grant funded by the Korean government (MSIP; no. 2019R1A2C2007216).

Conflicts of Interest: The authors declare no conflict of interest.

\section{References}

1. Wei, X.; Xiangning, X.; Pengwei, C. Overview of key microgrid technologies. Int. Trans. Electr. Energy Syst. 2018, 28, e2566. [CrossRef]

2. REN21. Renewables 2020 Global Status Report; REN21 Secretariat: Paris, France, 2020; ISBN 978-3-948393-00-7. Available online: http:/ /www.ren21.net/gsr-2020/ (accessed on 15 January 2021).

3. Rocabert, J.; Luna, A.; Blaabjerg, F.; Rodriguez, P. Control of Power Converters in AC Microgrids. IEEE Trans. Power Electron. 2012, 27, 4734-4749. [CrossRef]

4. Justo, J.J.; Mwasilu, F.; Lee, J.; Jung, J.W. AC-microgrids versus DC-microgrids with distributed energy resources: A review. Renew. Sustain. Energy Rev. 2013, 24, 387-405. [CrossRef]

5. Nasirian, V.; Shafiee, Q.; Guerrero, J.; Lewis, F.L.; Davoudi, A. Droop-Free Distributed Control for AC Microgrids. IEEE Trans. Power Electron. 2016, 31, 1600-1617. [CrossRef]

6. Alam, M.; Kumar, K.; Dutta, V. Analysis of solar photovoltaic-battery system for off-grid DC load application. Int. Trans. Electr. Energy Syst. 2021, 31, e12707. [CrossRef]

7. Liu, Y.; Yang, J.; Zhu, X.; Wang, Y.; He, B.; Zhu, J.; Chen, Y. Bi-level planning model for optimal allocation of WT-PV-ESS in distribution networks. J. Eng. 2017, 13, 1696-1701. [CrossRef]

8. Hirsch, A.; Parag, Y.; Guerrero, J. Microgrids: A review of technologies, key drivers, and outstanding issues. Renew. Sustain. Energy Rev. 2018, 90, 402-411. [CrossRef]

9. Lv, J.; Wang, X.; Wang, G.; Song, Y. Research on Control Strategy of Isolated DC Microgrid Based on SOC of Energy Storage System. Electronics 2021, 10, 834. [CrossRef] 
10. Elmouatamid, A.; Ouladsine, R.; Bakhouya, M.; Zine-Dine, K. A Predictive Control Strategy for Energy Management in Micro-Grid Systems. Electronics 2021, 10, 1666. [CrossRef]

11. Sun, Y.; Cai, Z.; Zhang, Z.; Guo, C.; Ma, G.; Han, Y. Coordinated Energy Scheduling of a Distributed Multi-Microgrid System Based on Multi-Agent Decisions. Energies 2020, 13, 4077. [CrossRef]

12. Thomas, D.; Deblecker, O.; Ioakimidis, C.S. Optimal design and techno-economic analysis of an autonomous small isolated microgrid aiming at high RES penetration. Energy 2016, 116, 364-379. [CrossRef]

13. Narayanan, V.; Kewat, S.; Singh, B. Solar PV-BES Based Microgrid System with Multifunctional VSC. IEEE Trans. Ind. Appl. 2020, 56, 2957-2967. [CrossRef]

14. Das, D.; Gurrala, G.; Shenoy, U.J. Transition between grid-connected mode and islanded mode in VSI-fed microgrids. Sādhanā 2017, 42, 1239-1250. [CrossRef]

15. Mongird, K.; Fotedar, V.; Viswanathan, V.; Koritarov, V.; Balducci, P.; Hadjerioua, B.; Alam, J. Energy Storage Technology and Cost Characterization Report; U.S. Department of Energy's Water Power Technologies Office by Pacific Northwest National Laboratory: Washington, DC, USA, 2019.

16. Wang, Z.; Chen, Y.; Mei, S.; Huang, S.; Xu, Y. Optimal expansion planning of isolated microgrid with renewable energy re-sources and controllable loads. IET Renew. Power Gener. 2017, 11, 931940. [CrossRef]

17. Bila, M.; Opathella, C.; Venkatesh, B. Grid-connected performance of a household lithium-ion battery energy storage system. J. Energy Storage 2016, 6, 178-185. [CrossRef]

18. Moncecchi, M.; Brivio, C.; Mandelli, S.; Merlo, M. Battery Energy Storage Systems in Microgrids: Modeling and Design Crite-ria. Energies 2020, 13, 2006. [CrossRef]

19. Mao, B.; Liu, C.; Yang, K.; Li, S.; Liu, P.; Zhang, M.; Meng, X.; Gao, F.; Duan, Q.; Wang, Q.; et al. Thermal runaway and fire behaviors of a $300 \mathrm{Ah}$ lithium ion battery with LiFePO4 as cathode. Renew. Sustain. Energy Rev. 2021, 139, 110717. [CrossRef]

20. Zubi, G.; Dufo-López, R.; Carvalho, M.; Pasaoglu, G. The lithium-ion battery: State of the art and future perspectives. Renew. Sustain. Energy Rev. 2018, 89, 292-308. [CrossRef]

21. Wang, Q.; Mao, B.; Stoliarov, S.I.; Sun, J. A review of lithium ion battery failure mechanisms and fire prevention strategies. Prog. Energy Combust. Sci. 2019, 73, 95-131. [CrossRef]

22. Galván, L.; Navarro, J.M.; Galván, E.; Carrasco, J.M.; Alcántara, A. Optimal scheduling of energy storage using a new prioritybased smart grid control method. Energies 2019, 12, 579. [CrossRef]

23. El-Shahat, A.; Sumaiya, S. DC-Microgrid System Design, Control, and Analysis. Electronics 2019, 8, 124. [CrossRef]

24. Chedid, R.; Sawwas, A.; Fares, D. Optimal design of a university campus micro-grid operating under unreliable grid consid-ering PV and battery storage. Energy 2020, 200, 117510. [CrossRef]

25. Mirhosseini, M. Sensitivity analysis, adaptability improvement and control of grid-connected photovoltaic power plants un-der grid frequency variations. Sol. Energy 2019, 184, 260-272. [CrossRef]

26. Karimi, Y.; Oraee, H.; Golsorkhi, M.S.; Guerrero, J.M. Decentralized Method for Load Sharing and Power Management in a PV/Battery Hybrid Source Islanded Microgrid. IEEE Trans. Power Electron. 2017, 32, 3525-3535. [CrossRef]

27. Mateska, A.K.; Borozan, V.; Krstevski, P.; Taleski, R. Controllable load operation in microgrids using control scheme based on gossip algorithm. Appl. Energy 2018, 210, 1336-1346. [CrossRef]

28. Pal, S.B.; Bhattacharya, K.D.; Mukherjee, D.; Paul, D. Estimation of Curve Tracing Time in Supercapacitor based PV Characterization. J. Inst. Eng. Ser. B 2017, 98, 385-391.

29. Chong, L.W.; Wong, Y.W.; Rajkumar, R.K.; Isa, D. An optimal control strategy for standalone PV system with batterySupercapacitor hybrid energy storage system. J. Power Sources 2016, 331, 553-565. [CrossRef]

30. Şahin, M.E.; Blaabjerg, F. A Hybrid PV-Battery/Supercapacitor System and a Basic Active Power Control Proposal in MATLAB/Simulink. Electronics 2020, 9, 129. [CrossRef]

31. Olivares, D.E.; Mehrizi-Sani, A.; Etemadi, A.H.; Canizares, C.A.; Iravani, R.; Kazerani, M.; Hajimiragha, A.H.; Gomis-Bellmunt, O.; Saeedifard, M.; Palma-Behnke, R.; et al. Trends in Microgrid Control. IEEE Trans. Smart Grid 2014, 5, 1905-1919. [CrossRef]

32. Tan, X.; Li, Q.; Wang, H. Advances and trends of energy storage technology in Microgrid. Int. J. Electr. Power Energy Syst. 2013, 44, 179-191. [CrossRef]

33. Rawa, M.; Abusorrah, A.; Al-Turki, Y.; Mekhilef, S.; Mostafa, M.H.; Ali, Z.M.; Aleem, S.H.E.A. Optimal Allocation and Economic Analysis of Battery Energy Storage Systems: Self-Consumption Rate and Hosting Capacity Enhancement for Microgrids with High Renewable Penetration. Sustainability 2020, 12, 10144. [CrossRef]

34. Abdulgalil, M.A.; Khalid, M. Enhancing the reliability of a microgrid through optimal size of battery ESS. IET Gener. Transm. Distrib. 2019, 13, 1499-1508. [CrossRef]

35. Dorahaki, S.; Dashti, R.; Shaker, H.R. Optimal energy management in the smart microgrid considering the electrical energy storage system and the demand-side energy efficiency program. J. Energy Storage 2020, 28, 101229. [CrossRef]

36. Silani, A.; Yazdanpanah, M.J. Distributed Optimal Microgrid Energy Management with Considering Stochastic Load. IEEE Trans. Sustain. Energy 2018, 10, 729-737. [CrossRef]

37. Kumar, P.S.; Chandrasena, R.P.S.; Ramu, V.; Srinivas, G.N.; Babu, K.V.S.M. Energy Management System for Small Scale Hybrid Wind Solar Battery Based Microgrid. IEEE Access 2020, 8, 8336-8345. [CrossRef]

38. Shreelakshmi, M.P.; Das, M.; Agarwal, V. Design and Development of a Novel High Voltage Gain, High-Efficiency Bidirectional DC-DC Converter for Storage Interface. IEEE Trans. Ind. Electron. 2018, 66, 4490-4501. [CrossRef] 
39. Hassan, W.; Soon, J.L.; Lu, D.D.-C.; Xiao, W. A High Conversion Ratio and High-Efficiency Bidirectional DC-DC Converter With Reduced Voltage Stress. IEEE Trans. Power Electron. 2020, 35, 11827-11842. [CrossRef]

40. Alramlawi, M.; Li, P. Design Optimization of a Residential PV-Battery Microgrid with a Detailed Battery Lifetime Estimation Model. IEEE Trans. Ind. Appl. 2020, 56, 2020-2030. [CrossRef]

41. Nadeem, F.; Hussain, S.M.S.; Tiwari, P.K.; Goswami, A.K.; Ustun, T.S. Comparative Review of Energy Storage Systems, Their Roles, and Impacts on Future Power Systems. IEEE Access 2019, 7, 4555-4585. [CrossRef]

42. Santos-Pereira, K.; Pereira, J.D.F.; Veras, L.S.; Cosme, D.L.S.; Oliveira, D.Q.; Saavedra, O.R. The requirements and constraints of storage technology in isolated microgrids: A comparative analysis of lithium-ion vs. lead-acid batteries. Energy Syst. 2021, 1-24. [CrossRef]

43. Saxena, S.; Xing, Y.; Kwon, D.; Pecht, M. Accelerated degradation model for C-rate loading of lithium-ion batteries. Int. J. Electr. Power Energy Syst. 2019, 107, 438-445. [CrossRef]

44. Rana, M.M.; Romlie, M.F.; Abdullah, M.F.; Uddin, M.; Sarkar, M.R. A Novel Peak Load Shaving Algorithm for Isolated Mi-crogrid Using Hybrid PV-BESS System. Energy 2021, 234, 121157. [CrossRef]

45. Kim, J.-M.; Lee, J.; Kim, J.-W.; Yi, J.; Won, C.-Y. Power Conversion System Operation to Reduce the Electricity Purchasing Cost of Energy Storage Systems. Energies 2021, 14, 4728. [CrossRef]

46. Castaño, S.P.; Gauchia, L.; Voncila, E.; Sanz, J. Dynamical modeling procedure of a Li-ion battery pack suitable for real-time applications. Energy Convers. Manag. 2015, 92, 396-405. [CrossRef]

47. Yang, Y.; Zhang, Y.; Tang, L.; Liu, T.; Peng, S.; Yang, X. Improved energy density and temperature range of vanadium redox flow battery by controlling the state of charge of positive electrolyte. J. Power Sources 2020, 450, 227675. [CrossRef] 